\title{
EDUCATION AND TRAINING
}

Much lip-service is paid to the concept of education. Philosophers advocate education as the means by which the full man is brought into being; economists accept education as a "merit good", which the individual should have even if he is not willing to purchase it for himself; social reformers see in education the most effective means of stimulating social mobility without damaging the essential fabric of society. Unfortunately, in the course of the last century, "education" and "schooling" have become synonymous, to the detriment of the former and the enhancement of the latter.

Formal, institutionalised, mass education in the form so familiar today derives only from the nineteenth century, from the Northern Europe of agricultural revolution, land enclosures, population growth, industrial revolution and a massive drift to the towns. The question is now beginning to be asked as to whether this structure should continue to dominate the field of education. On social, economic and political grounds it would appear that fundamental changes may be called for. Few countries today would claim that existing systems of formal education can respond to the tasks being required of them; fewer still would regard their educational systems as prime contributors to the society's well-being and stability.

Aims and objectives

Surveys in a number of countries in recent years make evident the confusion of aims attributed to schooling systems. What the school sets out to do does not always coincide with what parents and pupils hope to derive from it. For example, the Government Social Survey in Britain, in two reports dealing with different age-groups and educational levels, revealed that while school staffs rated examination success low in priority, most parents and many pupils considered it extremely important. For good or ill the public image of the school is of an institution which should prepare for employment and inculcate disciplined attitudes. Success in academic achievement in order to qualify for a remunerative occupation of high status is the desire of the majority of parents for their children. The young people themselves are perhaps increasingly ambivalent in their attitude towards school and their requirement from it. They seek an education which will enable them to live happily and serve their communities 
with pride and satisfaction, but they also seek qualifications granting the entrée to positions of security and profit. There is, too, a growing demand for the school to provide that guidance in the skills and art of living which used to come from the family and the Church.

In such a situation the role of the school becomes increasingly confused. Parents see in the school both the means by which their children can achieve material success and a disruptive influence on established family and community structures. Pupils see in the school a corridor of prolonged childhood down which it is necessary to pass uncritically in order to emerge as a young adult when the chrysalis of school uniform is shed. Formal education must be one of the few operations in which the requirements and predispositions of the consumer receive virtually no attention. A commercial organisation attempting to sell consumer-goods to young people without undertaking market research would be rightly condemned for irresponsible paternalism and a lack of professional acumen. It is perhaps strange that a form of schooling could have been decreed unilaterally without arousing similar reactions for a century and more.

Defining the objectives of education poses fewer problems than does elaborating the precise means by which these objectives may be attained. Few would question the desirability of educating for personal development and training to contribute to the future well-being and prosperity of the nation: the process by which this may be achieved is less sure. The balance between the education of the individual and the training of the citizen has to be struck, while the thorny question must be resolved as to the wisdom of encouraging the maximising of individual potential in the absence of likely social and economic opportunities for its expression. A redefinition of the objectives of education, composed afresh in the light of present circumstances, could benefit both providers and consumers.

Formal education

One marked manifestation of the gap in communication between older and younger people may be seen in the varying attitudes towards the formal educational process. The extent of the disillusion among students with existing systems of education and training is probably still underrated despite the accumulated evidence from all continents over the last five or six years. Educational providers, too, are looking ever more critically at 
the systems which they control, but they do not always see the same faults as the young people who are the receivers.

The criterion of an educational system should be its success in achieving its objectives, hence the prior need to define such objectives. In most countries today, however, it is apparent that formal education falls far short of its declared or implicit objectives of creating happy and responsible young adults, equal in opportunity and accurately graded in achievement, suitably guided towards a full and satisfying life role in their society. In the eyes of many educational providers and many informed onlookers, formal educational systems show themselves at best partially attuned to contemporary circumstances, unsuited in both content and form to individual and social needs, inefficient and wasteful of money and manpower. Only recently has the truth become evident that a declaration of aims does not in itself ensure that those aims will be achieved.

Significant changes in educational systems can rarely be brought about with speed, dependent as they are on retraining of teachers and the inculcation of new attitudes among teachers, the production of fresh materials and the provision of supporting funds. If changes are to be produced, therefore, controlling authorities must declare their commitment and accept the financial implications. The natural conservatism of teachers and public opinion must be recognised and the proposed innovations justified. All these processes will be that much easier if the fullest consultation has been undertaken with all interested parties from the earliest stages. Some of the reluctance to enter new financial commitments may be overcome by the incorporation in all new programmes of provision for periodic evaluation so as to measure the degree of success and make possible amendments during the course of the project.

In the Malta situation, state-organised pre-school provision was not thought to rate high priority, although measures might be introduced to ensure reasonable standards in those private classes which exist. By and large, Maltese pre-school children find ample informal opportunities to develop social and motor skills in their homes and immediate surroundings. It is at the primary stage that the first critical appraisal should be directed. Opinion at the seminar generally favoured a programme of primary education which would comprise a basic education common to all children. Refining of motor skills, developing skills and learning communication skills in the form of language, reading and writing, appeared to be the main objectives at the primary level. 
Education at the secondary level caused participants much concern, and a number of specific aspects were discussed at length, including questions of curriculum and examinations and problems relating to the transition from school to employment. It was generally agreed that the atmosphere in Maltese schools would be much healthier and the schools more effective if there were more informal contacts among teachers, pupils and parents. Opportunities for such contacts should be facilitated and encouraged by educational authorities, in the expectation that greater mutual confidence and respect would be inspired. Within the schools, new educational methods should be designed to meet the revised objectives, and curricula should be revitalised and reinforced by more imaginative teaching.

The content of secondary education was considered critically. Young people, it was thought, should receive much more guidance in the techniques of living. Secondary schools, for example, should include courses for potential consumers; courses in discrimination and the formation of rational judgment seemed essential to those young people exposed to the weight of attack by the mass media. The schools, too, should not ignore the very pertinent question of education for emigration, ensuring that the course-content had some relevance to the likely future environment of those students who would probably leave the islands.

Discontent seemed to be greatest with respect to the two issues of examinations and the transition from school to work. The constraints of external examinations appear to affect adversely the content and ambience of secondary education, resulting on the one hand in the perpetuation of outmoded syllabuses and on the other in the growth of a spare-time "cramming" industry conducted largely by teachers. Having passed successfully through the examination system, however, young people find not infrequently that higher levels of qualification give little advantage in obtaining jobs. In the situation pertaining in Malta at present young people of different academic standards are often employed in jobs of equal status, so bringing into question the practical worth of achieving scholastic success. On the other hand, academic qualifications are valued because social status is related in some measure to the level of education achieved.

The seminar felt that a revised system of secondary education should incorporate specialisation at a much later stage than that currently prevailing, so delaying the need for choice until each individual is of a maturity to appreciate the nature of various employment possibilities. Opportunities for changing specialisations should be available in order to minimise the effects 
of an initial unwise choice. Similarly, the examination system, which largely dictates the nature of the secondary school curriculum, should be thoroughly investigated, the content, form and standards of examinations redesigned in order to integrate them effectively with more relevant course content and make them more accurate measuring instruments.

It was agreed that some element of vocational bias could give added purpose to education. For this reason the proposed trade schools and technical institutes appeared likely to play a useful role, although the inculcation of new attitudes with regard to manual skills will present severe problems. Almost every country of the world has sought vainly to promote the dignity of manual labour. While manual labour carries with it low social status, lack of security and poor financial returns, no proclamations will alter attitudes. Only when action is taken to relieve these apparent disadvantages will manual occupations be upgraded. While the degree-holder is more highly rewarded than the holder of a technical qualification, while promotion leads inevitably from the workbench to the desk, manual and technical occupations will be rated as second-best. It may be that one of the essential steps in educating positive attitudes is for the government to reappraise the rewards given to its own employees in different categories.

Out of school education and training

While a range of facilities for education and training exists outside the formal system, it appears that there is need for a much greater degree of overall planning, co-ordination and co-operation. The situation is not unique to Malta: a recent report speaking generally of the current situation said,

"Formal education is accepted as the business and prerogative of the Ministry of Education; non-formal education, on the other hand, is practically everybody's business and therefore tends to be nobody's (especially when it comes to overall advocacy, planning and fund-raising.)"

Another recent report noted that there tends to be "complete ignorance of the total effort, money and manpower going into out of school education and training", although all the indications were that the amount was "grossly inadequate", and that little evaluation of programmes was carried out, so that the efficiency of the provision was not known. Initially, therefore, it would seem desirable for a comprehensive survey to be made of 
all non-formal educational activities in existence in the islands, ranging through general education (for early leavers, dropouts, those seeking higher qualifications), vocational training (apprenticeships, "learners", in-service and recycling provision), and social and welfare activities (leisure, recreation, sports, community service, compensatory and remedial provision).

Once the existing provision is known and the need assessed, the provision of an efficient and economical service becomes possible. Its efficiency and economy will have a direct relationship to that of the formal education system with which it should be linked to form one comprehensive national education service. Conditions change so rapidly that the concept of continuing education for all members of the community has become a necessity. As Professor Ben Morris wrote:

"There is no a priori reason why an educational system should take the form of a series of linear and end-on programmes beginning around five years and terminating for the 'elite' in the early twenties, and much earlier for others. It would seem much more realistic to consider the possibilities in terms of a multi-decker educational sandwich occupying a whole life-span."

To redesign the education system in this way would call for both a redeployment of funds and a reorientation of the attitudes of employers and the general public. To implement the revised design would involve a reconsideration of the teachers' role and make possible a much more intensive use of educational buildings and resources. Such a system would reduce the pressures on the child in the earlier years of his education, for his ten years of schooling would no longer be "make or break" for him; it would also reduce the importance of any policy to raise the school-leaving age, since further opportunities would open up to all young people.

Social and welfare activities

Non-educational facilities for young people have traditionally been the responsibility of voluntary organisations. Provision for pleasure, recreation, sports and social activities has grown up spasmodically under the aegis of the Church and of local groupings. Ine one of its aspects this provision reaches out to the potential delinquent and the "unclubbable", attempting thereby to prevent anti-social behavious and minimise personal stress and social tension. 
The three major requirements for successful youth services intended to provide for these needs are policy, money and personnel. The traditional activities and attitudes of youth services in many Commonwealth countries are now under close critical scrutiny; their image is being refashioned in response to present-day needs, particularly by the provision of facilities whereby young people can give direct service to their communities and feel that they are making a practical contribution to their own future. Such a refashioning of provision calls for the creation of a general youth policy, allowing for extensive local variations to meet expressed needs. A general policy, in turn, implies the existence of a representative body to determine and review that policy, providing counsel and guidance to all youth organisations.

Once youth services, acting in co-ordination, can be geared to revised plans linked to expressed needs, a reasonable case could be made for increased financial resources. Such a case would rest on the facts that activities were in response to known requirements, overlapping activities would be minimised and wastage reduced to the lowest practicable margin. Financing might be considered through the provision by the government of "matching" funds, whereby one or more voluntary groups would give proof of their good intent by raising themselves part of the finance necessary for their activity, the sum being matched by a governmental contribution. For such a system to be effective and recognised as equitable the central representative body proposed above would act as arbiter in deciding the worthiness of projects and programmes applying for matching funds.

The development of effective youth programmes depends in large measure on the training of high quality youth workers and the granting to them of professional status and commensurate rewards. It might be that the most appropriate means of training the high-level workers would be in association with the University or the Malta College of Arts, Science and Technology, where a basic course could be provided for a range of trainees - teachers, counsellors and guidance personnel, youth leaders, public health nurses, probation officers, social welfare workers - followed by specialised training in the particular fields.

If young people are to accept youth leaders, ideally the leaders should emerge as "graduates" of the youth services themselves. In the interim until this becomes possible older people may have to act as youth leaders. In this case they must not be too remote from the young people with whom they are working, and whose probable sense of impotence in the face of major social 
issues they must seek to turn to positive attitudes. A high degree of professional expertise, sympathy and the ability to exert unobtrusive influence are the essential qualities of the youth leader.

Immediate needs mentioned at the seminar were for improved youth centres, including the provision of residential facilities and study rooms. Were a realistic programme planned it might be possible for some at least of these additional facilities to be undertaken as self-help projects by the young people themselves. The involvement of young people in such activities would reinforce the need for them to participate fully in committees and councils affecting their lives. 